\title{
Retinal transcriptome profiling at transcription start sites: a cap analysis of gene expression early after axonal injury
}

Masayuki Yasuda', Yuji Tanaka', Koji M Nishiguchi,3, Morin Ryu', Satoru Tsuda', Kazuichi Maruyama and Toru Nakazawa ${ }^{1,2,3^{*}}$

\begin{abstract}
Background: Glaucoma is characterized by progressive loss of the visual field and death of retinal ganglion cells (RGCs), a process that is mediated, in part, by axonal injury. However, the molecular pathomechanisms linking RGC death and axonal injury remain largely unknown. Here, we examined these mechanisms with a cap analysis of gene expression (CAGE), which allows the comprehensive quantification of transcription initiation across the entire genome. We aimed to identify changes in gene expression patterns and to predict the resulting alterations in the protein network in the early phases of axonal injury in mice.

Results: We performed optic nerve crush (ONC) in mice to model axonal injury. Two days after ONC, the retinas were isolated, RNA was extracted, and a CAGE library was constructed and sequenced. CAGE data for ONC eyes and sham-treated eyes was compared, revealing 180 differentially expressed genes. Among them, the Bcat 1 gene, involved in the catabolism of branched-chain amino acid transaminase, showed the largest change in expression (log2 fold-change $=6.70$ ). In some differentially expressed genes, alternative transcription start sites were observed in the ONC eyes, highlighting the dynamism of transcription initiation in a state of disease. In silico pathway analysis predicted that ATF4 was the most significant upstream regulator orchestrating pathological processes after ONC. Its downstream candidate targets included Ddit3, which is known to induce cell death under endoplasmic reticulum stress. In addition, a regulatory network comprising IFNG, P38 MAPK, and TP53 was predicted to be involved in the induction of cell death.
\end{abstract}

Conclusion: Through CAGE, we have identified differentially expressed genes that may account for the link between axonal injury and RGC death. Furthermore, an in silico pathway analysis provided a global view of alterations in the networks of key regulators of biological pathways that presumably take place in ONC. We thus believe that our study serves as a valuable resource to understand the molecular processes that define axonal injury-driven RGC death.

Keywords: CAGE, Cap analysis of gene expression, Transcription start sites, Transcriptome, Axonal injury, Optic nerve crush, Retinal ganglion cells, RGC

\footnotetext{
* Correspondence: ntoru@oph.med.tohoku.ac.jp

1Department of Ophthalmology, Tohoku University Graduate School of

Medicine, 1-1 Seiryo-machi, Aoba-ku, Sendai, Miyagi 980-8574, Japan

${ }^{2}$ Department of Retinal Disease Control, Tohoku University Graduate School

of Medicine, 1-1 Seiryo-machi, Aoba-ku, Sendai, Miyagi 980-8574, Japan

Full list of author information is available at the end of the article
} 


\section{Background}

Glaucoma, one of the leading causes of blindness worldwide [1], is accompanied by unique progressive morphological changes in the optic nerve head, termed "glaucomatous optic neuropathy". These changes are associated with characteristic patterns of visual field defects [2]. The contribution of elevated intraocular pressure (IOP) to glaucoma development and progression is well established, and currently available treatments have focused almost entirely on lowering IOP [3]. However, reported data have clearly demonstrated that even a substantial reduction in IOP cannot halt disease progression in many cases, which has led to increased attention to IOP-independent risk factors for glaucoma [4]. The understanding that glaucoma is a multifactorial disease has been solidified by strong clinical evidence suggesting that high myopia [5], age [6], reduced ocular blood flow [6], and axonal injury [7] may exacerbate glaucoma independently of IOP. Thus, in order to improve the management of glaucoma and mitigate the associated risk of blindness, it is important to improve our understanding of the pathologies that lead to deterioration in vision independently of IOP.

Axonal injury, possibly related to structural changes in the lamina cribrosa, has been proposed as an IOP-independent factor contributing to glaucoma [8-12]. Histopathological analysis has shown that mechanical stress on the axon bundles at the optic nerve head may occur in patients with glaucoma [13]. While such structural changes may be the consequence of age-related degenerative processes [14-17], factors such as ischemia [18,19], inflammation [20,21], and oxidative stress $[22,23]$ may also contribute. Moreover, axonal injury has been suggested to precede visual field defects in glaucoma patients [24]. However, little is known about the molecular events that link the injury to the axonal bundles and the death of RGCs (the proximal cause of glaucoma).

One of the most effective approaches to understand the molecular events that cause RGC death after axonal injury is comprehensive gene expression analysis using animal models. Most past studies that analyzed molecular events after axonal injury to the optic nerve in animal models took a targeted approach, in which one or, at most, a few molecules were selected for characterization [25]. Conversely, results obtained through microarray analysis have provided a list of many candidate genes that may be involved in the death of RGCs, providing a global view of change in gene transcription $[26,27]$. However, microarray analyses rely on the hybridization of a set of known transcripts and are not as comprehensive as sequencing-based techniques [28]. In order to overcome this problem, we recently performed RNA sequencing (RNA-seq) using a next-generation sequencer on the eyes of mice which had undergone optic nerve crush (ONC) [29]. Profiling gene expression in these eyes uncovered a number of differentially expressed genes
(DEGs) that may characterize ongoing biological processes in the ONC. Nevertheless, this technique relies on the comprehensive sequencing of random fragments of RNA with little attention to transcription start sites (TSSs) [28]. From this perspective, cap analysis of gene expression (CAGE) can be considered a complementary technique to RNA-seq, as CAGE analysis depends on the construction of full-length cDNA libraries and counting of the short tags at the $5^{\prime}$ end of the transcripts [30,31]. In this way, the distribution of TSSs and networks of gene transcription can be studied comprehensively and quantitatively on a genome-wide scale. CAGE analysis is more efficient than conventional Rapid Amplification of cDNA End or EST analysis, as high throughput is possible at a relatively low cost [32]. The usefulness and power of this technique have been widely recognized through its contribution to the "Encyclopedia of DNA Elements" (ENCODE) project, which elucidated the global distribution of promoter areas in the human genome and the regulatory network of transcription factors [33,34].

In this study, we applied CAGE analysis to retinal samples 2 days after ONC, in order to comprehensively study changes in gene transcription at TSSs. Using CAGE data, we attempted to determine dynamic changes in the regulation of the transcriptional network mediating RGC death after axonal injury.

\section{Methods}

\section{Animals}

Forty-six C57BL/6 mice (male, 12 weeks old; SLC, Hamamatsu, Japan) were used in this study. The surgical procedures were performed under deep anesthesia, which used intramuscular administration of a mixture of ketamine $(100 \mathrm{mg} / \mathrm{kg})$ and xylazine $(9 \mathrm{mg} / \mathrm{kg})$. All animals were maintained and handled in accordance with the guidelines of the ARVO Statement for the Use of Animals in Ophthalmic and Vision Research and the guidelines from the Declaration of Helsinki. All experimental procedures described in the present study were approved by the Ethics Committee for Animal Experiments at Tohoku University Graduate School of Medicine.

\section{Induction of axonal injury}

Axonal injury was induced by $\mathrm{ONC}$ as previously described [25,35]. Briefly, the optic nerve was exposed, and then crushed $2 \mathrm{~mm}$ posterior to the globe with fine forceps for 10 seconds. We confirmed that retinal blood circulation was normal with a fundus examination, and then applied antibiotic ointment. We also performed sham operations on a separate group of mice, in which the procedure was similar but the optic nerve was not crushed. 


\section{RNA preparation}

Total RNA was purified from each retinal sample as previously described [29]. Two days after surgery, the retinas were extracted and immediately immersed in RNAlater RNA Stabilization Reagent (Qiagen, Valencia, CA). The retinas were then homogenized in Qiazol (Qiagen) with a pestle homogenizer, and total RNA was extracted from the homogenized mixture with a miRNeasy mini kit (Qiagen). The resulting 46 individual samples (23 in each group) were then assessed with a spectrophotometer to estimate their total RNA concentration (NanoDrop 2000c, Thermo Scientific). To prepare the RNA samples for CAGE, fixed quantities of RNA were taken from six samples and combined into a single sample, in order to minimize the influence of individual variations in the mice [29]. The quality of these six combined RNA samples was then assessed with an Agilent 2100 Bioanalyzer (Agilent Technologies). The RNA integrity number of each combined sample used for the cDNA preparation is shown in Additional file 1.

\section{CAGE library preparation and sequencing}

A CAGE cDNA library was prepared as previously described [36,37], with minor adaptations for the Illumina sequencer platform [38]. Five $\mu \mathrm{g}$ of RNA from each retinal sample were used to synthesize single-strand cDNA. The cDNA was then reverse-transcribed with a random primer N6 primer (5'-TCTNNNNNN-3'). The resulting cDNA/RNA hybrids were oxidized with $\mathrm{NaIO}_{4}$ in order to open the diol at the $5^{\prime}$ end on the cap structure, and the diol group at the $3^{\prime}$ end of each RNA strand. The derived oxidized dialdehyde of the cap site and 3' ends of the RNA strands were biotinylated with biotin (long arm) hydrazide (Vector Laboratories) and treated with RNaseONE (Promega) in order to remove the 3' end of each RNA strand and the biotinylated cap when cDNA failed to reach the $5^{\prime}$ ends. The biotinylated $5^{\prime}$ end of each RNA strand was selectively trapped with magnetic streptavidin beads (Dynabeads MyOne Streptavidin C1 beads, Life Technologies). The captured cDNA was then released from the beads with RNaseONE treatment, and the single-strand cDNA was purified with Agencourt AMPure XP (Beckman Coulter) according to the manufacturer's instructions. A $5^{\prime}$ linker with a barcoded sequence was ligated to the $5^{\prime}$ end of the cDNA. The cDNA was purified with Agencourt AMPure XP, and then a $3^{\prime}$ linker containing an Illumina adapter sequence was ligated to it. The cDNA was again purified with Agencourt AMPure XP, followed by treatment with Shrimp Alkaline Phosphatase (Affymetrics) and USER (NEB) to restrict the upper strand of the 3' linker. Secondstrand cDNA was synthesized with a second primer consisting of another Illumina adapter sequence. After Exonuclease I (NEB) treatment, the resulting second-strand cDNA was purified with Agencourt AMPure XP. The cDNA concentration of the final product was determined with a Quant-iT PicoGreen dsDNA Assay Kit (Life Technologies).

Cluster generation of the cDNA was performed with a cBot fluidics device and the Illumina cBot software. One lane of the flow cell was used for sequencing with fourcolor DNA Sequencing-By-Synthesis (SBS) technology using the Illumina HiSeq 2000 (Illumina, San Diego, $\mathrm{CA}$ ). The sequencing run and the base call analysis were performed according to the manufacturer's protocol with a TruSeq SBS kit v3-HS (Illumina). After the sequencing, raw sequence data were generated by Illumina RTA 1.12.4.2 and CASAVA-1.8.2. The sequence data were recorded as FASTQ files. All CAGE sequence data are available under the accession number DRA002410.

\section{CAGE data processing and differential expression analysis}

For processing and analysis of sequenced CAGE data, we used an integrated platform provided by the Data Analysis Center of the Cell Innovation Program (http:// cell-innovation.nig.ac.jp). The overall workflow is shown in Additional file 2. Primary data processing of the sequenced data was performed with the nAnT-iCAGE pipeline [36]. Read alignment and sequence mapping were performed with BWA software [39]. All sequence reads were mapped to the reference genome (NCBI37/ $\mathrm{mm} 9$ ). The mapped data were recorded in the SAM format file, and converted to BAM files with SAMtools [40]. The mapping quality was assessed with SAMStat software [41]. All the processed data in the BAM files were imported to a RECLU pipeline [42]. The RECLU is a method of implementing clustering, differential expression analyses, and motif discovery analyses. The core steps of the RECLU pipeline include clustering of individual TSSs with a modified version of the Paraclu algorithm, merging overlapping peaks in different replicates and applying an irreproducible discovery analysis (IDR) to select reproducible peaks [42-44]. In order to apply the Paraclu methods to CAGE datasets, the mapped reads were converted into the CAGE-defined transcriptional start sites format. The mapped reads at each site were counted with SAMtools. In the modified Paraclu program, a normalized tag per million (TPM) per base threshold was used and clusters with $<0.1$ TPM per base were omitted [42]. Both the original and modified Paraclu programs define clusters as maximal scoring segments, found by varying a density parameter (d) $[43,45]$. In this study, the stability of each cluster, defined as $\max \mathrm{d} / \mathrm{min} \mathrm{d}$, was calculated with the modified Paraclu program. If a particular segment had maximal scoring over a large range of values for $\mathrm{d}$, we considered it to be a stable cluster [42]. The IDR is a reproducibility criterion analogous to the false discovery rate (FDR) [44]. We only selected clusters with an IDR $<0.1$. Differential gene expression analysis was performed with the 
Bioconductor package 'edgeR' [46]. DEGs were defined as having an FDR adjusted $P$-value $<0.05$ along with absolute fold-change $>1.5$. The AMD [47], GLAM2 [48], Weeder [49], and DREME [50] programs were used to identify motifs [42], and the Tomtom program [51] was used to compare standard motif representations in the JASPAR core database [52].

\section{Quantitative real-time PCR}

Ten samples of purified RNA ( $\mathrm{n}=5$ in each group) were used in a quantitative real-time PCR (qRT-PCR) analysis. Total RNA (200 ng per sample) from each sample was reverse-transcribed into cDNA using SuperScript III (Invitrogen Life Technologies, Carlsbad, CA). QRT-PCR was then performed with a 7500 Fast Real-Time PCR System
(Applied Biosystems, Foster City, CA) as previously described [53]. For each $20 \mu \mathrm{l}$ reaction the following were used: $10 \mu \mathrm{l}$ TaqMan Fast Universal PCR Master Mix (Applied Biosystems, Foster City, CA), $1 \mu \mathrm{l}$ Taqman probe, $1 \mu \mathrm{l}$ template DNA, and $8 \mu \mathrm{L}$ DEPC water. For a relative comparison of gene expression, we analyzed the results of the qRT-PCR data with the comparative Ct method $\left(2^{-\Delta \Delta C T}\right)$, normalized to Gapdh, an endogenous control. All Taqman probes used for these reactions are listed in Additional file 3.

\section{Pathway analysis}

In silico pathway analyses were performed with Ingenuity Pathway Analysis (IPA, Ingenuity Systems, Redwood City, CA) as previously described $[29,54,55]$. The DEG datasets were uploaded to the IPA application and mapped to the

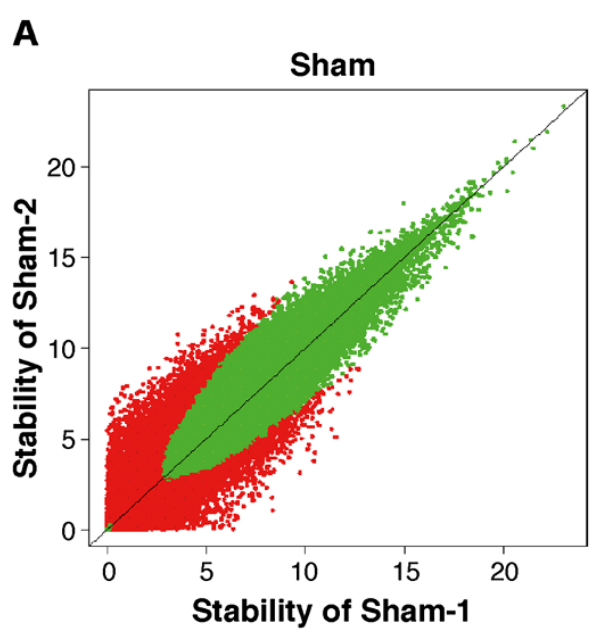

C

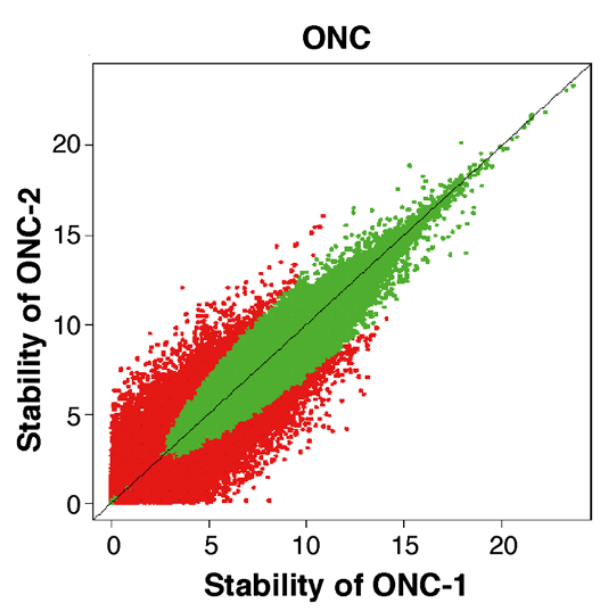

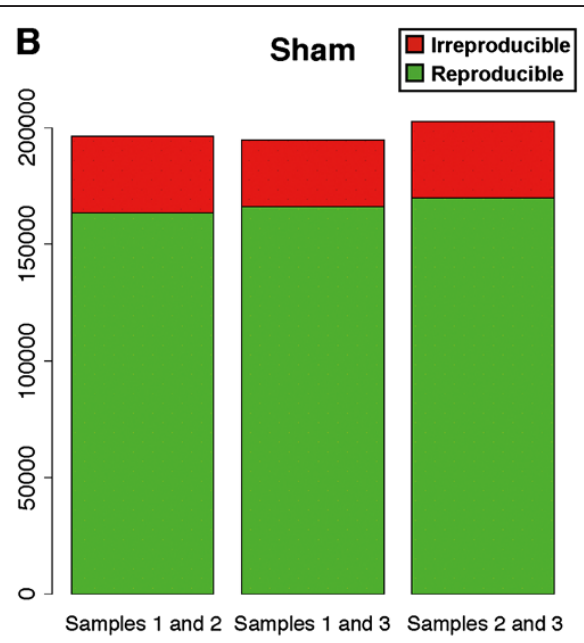

D
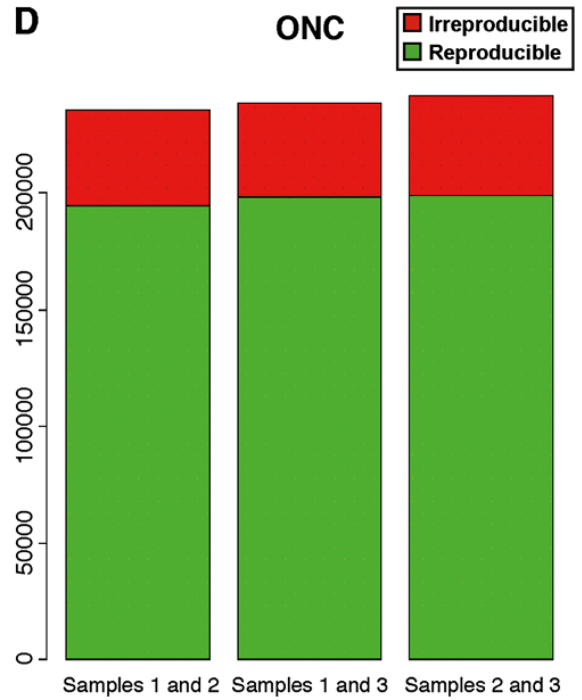

Figure 1 Stability and reproducibility of the biological replicates used for CAGE. The scatter plots show the correlation between expression values in replicates 1 and 2 in both the sham (A) and ONC (C) groups. Stability is a score used for clustering reproducible TSSs in multiple replicates. Green dots indicate high reproducibility and red dots indicate low reproducibility. The bar graphs represent a reproducibility evaluation for each pair of replicates in the sham (B) and ONC (D) groups. Green indicates TSS clusters with high reproducibility between the replicates. Red indicates TSS clusters with low reproducibility between the replicates. 
Ingenuity Pathways Knowledge Base (IPKB). Each gene identifier was then mapped to its corresponding IPKB. Duplication of genes in the DEG datasets was resolved by selecting the gene with the maximum fold-change value [56]. Networks of these genes were generated based on their connectivity. The significance of the association between the datasets and biofunctions was measured as the ratio of the number of genes from the dataset that mapped to the pathway divided by the total number of genes in that pathway. An upstream regulator analysis was performed to compare DEGs in the datasets to those known to be regulated by a given upstream regulator. Based on the concordance between them, an activation score was assigned, showing whether a potential transcriptional regulator was in an "activated" (z-score $\geq 2$ ), "inhibited" (z-score $\leq-2$ ), or uncertain state. The regulator effects analysis was also performed with IPA, in order to discover relationships between upstream regulators and downstream functions and diseases. Only regulators and downstream functions and diseases with $P<0.05$ and $\mid \mathrm{z}$ - score $\mid \geq 2$ were used in this analysis. The regulator effects algorithm connects upstream regulators, dataset molecules and downstream functions or diseases affected in the dataset to generate a hypothesis that can explain how the upstream regulators affect the downstream target molecule expression and the impact of the molecular expression on functions and diseases. The consistency score, a measure of the causal consistency and density of connection in a regulator effects network, was also calculated with IPA.

\section{Statistical analysis}

Differential gene expression analysis of CAGE data was performed with the $\mathrm{R}$ Bioconductor package 'edgeR' integrated in the RECLU pipeline, as described above. $P$ values were adjusted for multiplicity with Benjamini-
Hochberg correction with edgeR. Genes with adjusted $P$-values $<0.05$ and absolute fold-change $>1.5$ were considered DEGs in the CAGE analysis.

QRT-PCR data were analyzed with the Welch's $t$-test. Statistical analysis of the qRT-PCR data was performed with $R$ software (version 3.1.0) [57]. The significance of the pathway analysis was calculated with Fisher's exact test in the IPA application. If the P-values for qRT-PCR and IPA were less than 0.05 , the results were considered statistically significant.

\section{Results}

\section{Validation of the CAGE data}

Previously, we obtained experimental data indicating that RGC death starts approximately 3 days after ONC in mice [25]. As our primary interest was to use the CAGE data to search for therapeutic targets for RGC preservation, we examined changes in the retina on 2 days after ONC (Day 2), in order to observe the molecular events preceding the actual death of the cells. Total RNA was extracted from 3 independent retinal samples, each of which was derived from 6 retinas extracted from 6 different mice. CAGE was then performed on these 3 samples. The analysis workflow for the data derived from CAGE is well established [42]. An outline of the process is shown in Additional file 2.

Before beginning the analysis of the CAGE data, we evaluated its integrity (Additional file 1). We found that, in all samples, at least $89.8 \%$ of the sequence data mapped to the reference genome $(\mathrm{NCBI} 37 / \mathrm{mm} 9)$, assuring that the overall quality of the CAGE data was high. Furthermore, the MAPQ value, which represents the mapping quality of each sample, was more than 30 in at least $75.3 \%$ of the mapped data. Finally, we tested the gross consistency of the data among biological samples by comparing pairs of expression

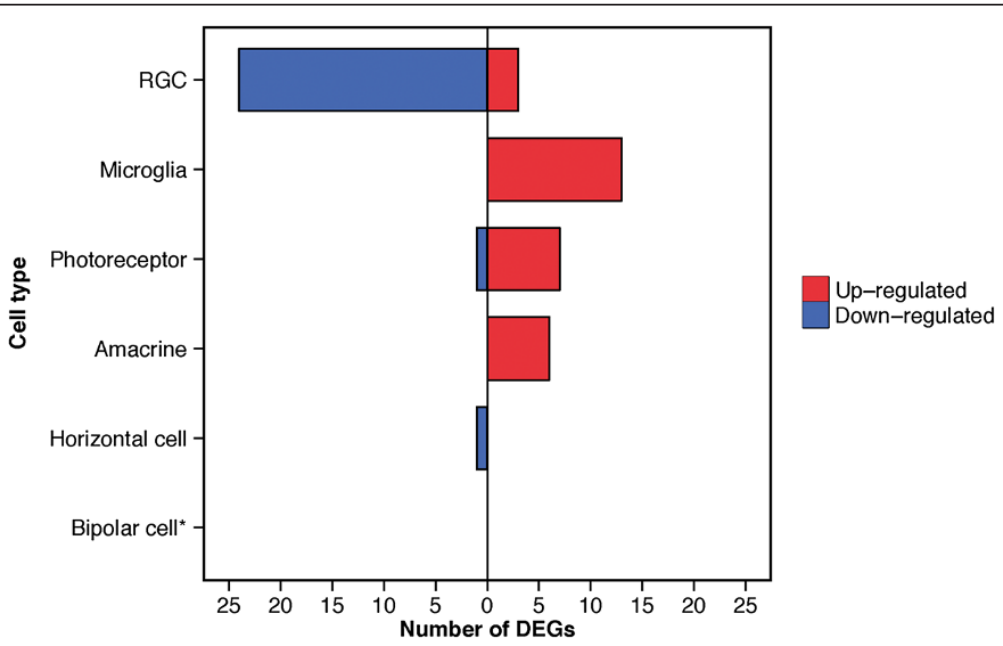

Figure 2 Overall reduction in the RGC-specific transcriptome. The horizontal histogram shows the number of DEGs in each retinal cell type [59]. Red: up-regulated, Blue: down-regulated. *No DEGs specific to bipolar cells were detected in this study. 

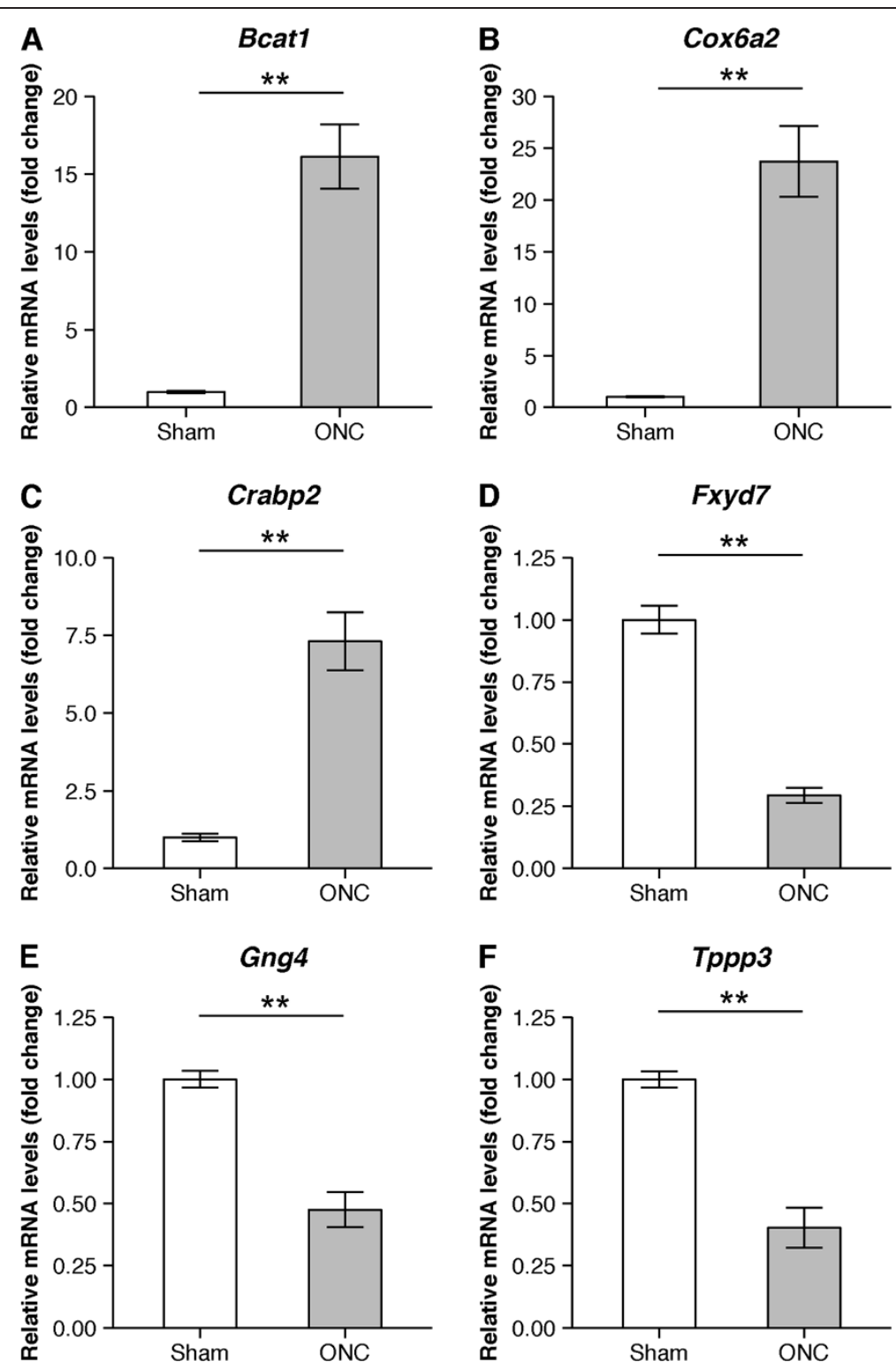

Figure 3 Validation of selected DEGs with qRT-PCR. Transcriptional changes in six selected DEGs were validated with qRT-PCR (A-F). The graphs show the level of mRNA expression in the ONC group relative to the sham group. The average expression for sham group was normalized as a 1.0-fold change. Values are mean $\pm \mathrm{SD}\left(\mathrm{n}=5\right.$ in each group, $\left.{ }^{* *} \mathrm{P}<0.01\right)$.

data derived from each treatment group using the modified Paraclu and the IDR program in the RECLU pipeline. The IDR analysis was used to quantitatively measure consistency between biological replicates and to select reproducible signals. These analyses revealed that the expression patterns in sets of data derived from independent samples taken from the same group were highly similar (Figure 1), assuring the high integrity of the CAGE datasets. Taken together, the quality of the data thus met the reliability requirements for downstream processing $[41,58]$.

\section{Comparative analysis of DEGs}

After assessing the quality of the CAGE data and defining the TSSs of our data, we used the edgeR package to perform a differential expression analysis of the transcripts at each TSS in the eyes subjected to ONC and the eyes that received a sham procedure. Consequently, we identified 400 differentially expressed TSSs, which included 180 annotated (Additional file 4) and 220 unannotated TSS clusters (Additional file 5). We further divided the 180 annotated DEGs into 6 groups of genes based on their retinal cell 
Table 1 Top 10 up- and down-regulated genes in each peak type after ONC

\begin{tabular}{|c|c|c|c|}
\hline Gene & Gene accession & $\log _{2}$ fold-change & Adjusted $P$-value \\
\hline \multicolumn{4}{|c|}{ Up-regulated at top peaks } \\
\hline Bcat1 & NM_007532 & 6.70 & 7.80E-04 \\
\hline Sprria & NM_009264 & 4.66 & $1.80 \mathrm{E}-23$ \\
\hline Mmp12 & NM_008605 & 4.36 & $1.70 \mathrm{E}-39$ \\
\hline Adcyap 1 & NM_009625 & 4.27 & 7.10E-08 \\
\hline Zfp275 & NM_001160229 & 3.88 & 3.50E-02 \\
\hline Ecel1 & NM_001277925 & 3.60 & 2.00E-07 \\
\hline Crabp2 & NM_007759 & 3.56 & $2.60 \mathrm{E}-10$ \\
\hline Arhgef2 & NM_001198911 & 3.53 & $2.40 \mathrm{E}-02$ \\
\hline Gal & NM_010253 & 3.49 & 7.60E-07 \\
\hline Asns & NM_012055 & 3.44 & $3.50 \mathrm{E}-06$ \\
\hline \multicolumn{4}{|c|}{ Up-regulated at bottom peaks } \\
\hline Sprria & NM_009264 & 4.76 & $3.90 \mathrm{E}-31$ \\
\hline Mmp12 & NM_008605 & 4.14 & $1.80 \mathrm{E}-51$ \\
\hline Ecel1 & NM_001277925 & 3.74 & $1.60 \mathrm{E}-20$ \\
\hline Crabp2 & NM_007759 & 3.55 & $2.40 \mathrm{E}-11$ \\
\hline Gal & NM_010253 & 3.49 & $1.80 \mathrm{E}-18$ \\
\hline Cox6a2 & NM_009943 & 3.25 & $2.50 \mathrm{E}-11$ \\
\hline Thoc7 & NM_001013578 & 3.21 & $9.10 \mathrm{E}-03$ \\
\hline Zfand $2 b$ & NM_026846 & 3.20 & $2.00 \mathrm{E}-04$ \\
\hline Tnfrsf12a & NM_001161746 & 2.95 & $6.60 \mathrm{E}-06$ \\
\hline Arhgef2 & NM_001198911 & 2.92 & $3.00 \mathrm{E}-09$ \\
\hline \multicolumn{4}{|c|}{ Down-regulated at top peaks } \\
\hline Gng4 & NM_010317 & -6.39 & 7.50E-03 \\
\hline Ak4 & NM_009647 & -3.45 & $2.50 \mathrm{E}-02$ \\
\hline Ndufa13 & NM_023312 & -3.02 & $3.10 \mathrm{E}-02$ \\
\hline Tusc5 & NM_177709 & -2.40 & $1.70 \mathrm{E}-04$ \\
\hline Nrgn & NM_022029 & -2.20 & $8.00 \mathrm{E}-03$ \\
\hline Fxyd7 & NM_022007 & -2.15 & $7.50 \mathrm{E}-12$ \\
\hline Ctxn3 & NM_001134697 & -2.09 & 4.60E-03 \\
\hline Tppp3 & NM_026481 & -1.58 & $3.00 \mathrm{E}-02$ \\
\hline Pvalb & NM_013645 & -1.53 & $1.80 \mathrm{E}-05$ \\
\hline Sncg & NM_011430 & -1.46 & 4.60E-03 \\
\hline \multicolumn{4}{|c|}{ Down-regulated at bottom peaks } \\
\hline Scarna9 & NR_028568 & -2.66 & $3.10 \mathrm{E}-02$ \\
\hline Tusc5 & NM_177709 & -2.43 & 9.10E-06 \\
\hline Cnn3 & NM_028044 & -2.41 & $8.60 \mathrm{E}-03$ \\
\hline Fxyd7 & NM_022007 & -1.62 & $4.50 \mathrm{E}-13$ \\
\hline Ctxn3 & NM_001134697 & -1.58 & $1.80 \mathrm{E}-04$ \\
\hline Rasgrp2 & NM_011242 & -1.47 & 2.20E-07 \\
\hline Tmsb10 & NM_001039392 & -1.44 & $4.50 \mathrm{E}-05$ \\
\hline
\end{tabular}


Table 1 Top 10 up- and down-regulated genes in each peak type after ONC (Continued)

\begin{tabular}{llll}
\hline BCl2 & NM_009741 & -1.43 & $6.80 \mathrm{E}-03$ \\
1500009C09Rik & NR_037698 & -1.41 & $4.30 \mathrm{E}-05$ \\
Oasl1 & NM_145209 & -1.34 & $4.30 \mathrm{E}-05$ \\
\hline
\end{tabular}

Differences were considered significant with an adjusted $P$-value $<0.05$ and |fold-change| $>1.5$.

type, i.e., RGCs, microglia, photoreceptors, amacrine cells, horizontal cells, and bipolar cells, using published microarray gene expression data [59]. According to the microarray database, 55 of 180 DEGs were expressed more specifically in one of the first 5 of these retinal cell types (Additional file 6). However, no DEGs specific to bipolar cells were detected in this study. We found that $88.9 \%$ of the genes that were relatively specific to RGCs were downregulated in the ONC retinas, which was in sharp contrast with other cell types studied (Figure 2). This pattern of expression is, in fact, in good agreement with the expected reduction of transcription in severely injured RGCs [60,61], further validating the biological accuracy of the CAGE data.

Next, we determined if there were specific correlations between the level of transcripts at a given TSS and the level of transcripts detectable by qRT-PCR. The expression of six randomly selected highly significant DEGs (Bcat1, Cox6a2, Crabp2, Fxyd7, Gng4 and Tppp3) was quantified by choosing the primer pair downstream of the TSS of interest. Conventional qRT-PCR showed a significant difference in expression in the six genes in the sham-treated and ONC samples (Figure 3). This was consistent with the differential expression patterns observed in the CAGE data.

The type of TSS could also be further classified based on the distribution of the mapped tags forming two different types of clusters with sharp TATA-box-associated promoters (top peaks) and broad CpG-associated promoters (bottom peaks) ([62]) (Additional file 7). The 10 most significantly up- or down-regulated DEGs at the top and bottom peaks are shown in Table 1 . We found that $45 \%$ of the top 10 up-regulated DEGs and 55\% of the top 10 down-regulated DEGs at either or both peaks after ONC were also up-regulated in the RNAseq data derived from the same model [29]. Meanwhile, 75\% of the up-regulated DEGs and $45 \%$ of the down-regulated
DEGs were also identified as DEGs in the microarray data derived from mouse retinas 3 days after ONC, one day later than the current study [27].

In some DEGs, we found evidence of the emergence of alternative promoters after ONC. For example, in the sham-treated eyes, transcription of Tnfrsf $12 a$ was almost exclusively dependent on the TSS of exon 1 of the reference transcript (NM_013749). However, in the retinal samples from the ONC eyes, a cryptic promoter embedded around exon 2 emerged as an equally dominant TSS (Additional file 8). We also performed a promoter database search with ZENBU [63], which contains FANTOM5 (Functional Annotation of Mammalian Genome 5) datasets [64]. According to ZENBU, the use of this Tnfrsf $12 a$ promoter has been already recognized in hepatocyte and Schwann cells.

Furthermore, we discovered that 34 of the 220 unannotated TSS clusters differentially expressed 2 days after ONC did not have any CAGE peaks in ZENBU (Additional file 5). These 34 TSS clusters may therefore include novel promoters and/or novel long non-coding RNAs specifically affected by axonal injury. We investigated the tissue specificity of the remaining 186 unannotated TSSs registered in ZENBU. However the database did not contain specific expression profile data for the retina, but only for the whole eye. According to ZENBU, 6 of the 186 unannotated TSSs were specifically expressed in the murine eye (Additional file 5).

\section{In silico pathway analysis of the DEGs}

An in silico pathway analysis of the bioinformatics of the 180 DEGs revealed five potential biological processes that occurred differentially in the retinas of the $\mathrm{ONC}$ and sham-treated groups. Among these processes, 42 DEGs contributing to the "Cell Death and Survival" pathway emerged as the most significant (Table 2). Since

Table 2 Top 5 molecular and cellular biological pathways significantly altered after ONC

\begin{tabular}{lll}
\hline Category & $P$-value & Number of molecules \\
\hline Cell death and survival & $1.99 \mathrm{E}-09-7.11 \mathrm{E}-03$ & 42 \\
Cellular development & $1.51 \mathrm{E}-05-7.11 \mathrm{E}-03$ & 24 \\
Cellular growth and proliferation & $1.51 \mathrm{E}-05-7.11 \mathrm{E}-03$ & 32 \\
Cell-to-cell signaling and interaction & $2.11 \mathrm{E}-05-7.11 \mathrm{E}-03$ & 30 \\
Cellular function and maintenance & $2.18 \mathrm{E}-05-7.11 \mathrm{E}-03$ & 32 \\
\hline
\end{tabular}


one of our main goals was to understand the molecular network that mediates the death of RGCs in axonal injury, we took a deeper look into the DEGs that contributed to this pathway (Additional file 9). Based on the information in Additional files 4 and 9, we generated a file that lists the DEGs in the "Cell Death and Survival" pathways, and indicates their involvement in the "Cell death" and "Cell survival" pathways, as well as their gene expression changes 2 days after ONC (Additional file 10). We found that the endoplasmic reticulum (ER) stress-related genes Atf3, Ddit3, Egr1 and Jun [65,66], which belong to the cell death pathway, were upregulated 2 days after $\mathrm{ONC}$ (Additional file 10). Bbc3, a pro-apoptotic BH3-only gene [67] was also up-regulated (Additional file 4). Additionally, Bcl2 [68], Park7 [69] and Serpinf1 [70], which belong to the cell survival pathway, had altered expression 2 days after ONC: Bcl2 was down-regulated, whereas Park7 and Serpinf1 were upregulated (Additional file 10).

For the purpose of selecting therapeutic targets, it is useful to understand the hierarchy of a defined molecular network. Therefore, we performed an additional in silico analysis to identify the key upstream regulators that govern these networks [71]. This analysis revealed six important upstream regulators, each predicted to act upon different sets of target molecules, likely mediating different biological

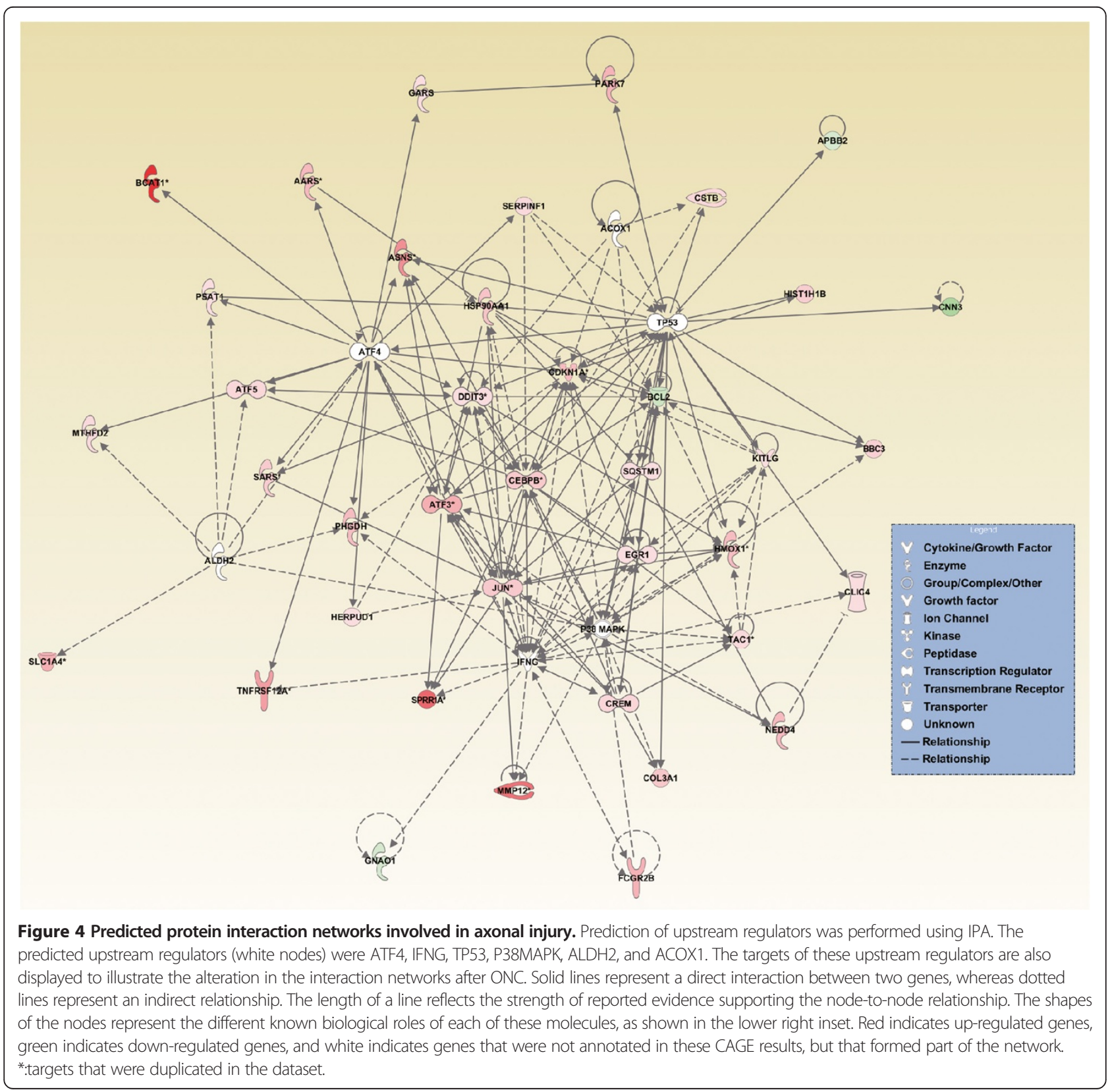


effects (Figure 4, Table 3). Additionally, the regulator effects analysis predicted that a regulatory network comprising IFNG, P38 MAPK, and TP53 was involved in cellular death (Additional file 11).

An alternative way to search for key upstream transcription factors defining the pathology of ONC eyes is to explore the dominant binding motifs embedded near the TSS. For this purpose, we took advantage of a previously established program [51] to predict the motifs to which the transcription factor bound. Target motifs were recovered for each of the four patterns of quantitative change in transcription (Table 4 and Additional file 12). This information predicted that 5 transcription factors (SP1, PAX4, RREB1, Tal1/Gata1 complex and NFATC2) interacted with the recovered motifs and exerted biological effects contributory to the process of axonal injury.

\section{Discussion}

In this study, CAGE analysis was performed on retinal RNA samples collected 2 days after the ONC procedure, to comprehensively and quantitatively compare TSSs scattered throughout the genome and elucidate the molecular pathomechanisms underlying the RGC death induced by axonal injury. Through the use of a unique analysis pipeline, our study identified a list of DEGs with high value.

On a global level, we observed that transcription of DEGs in the RGCs was generally depressed. This pattern of expression change was unique to DEGs in the RGCs, as DEGs in the other cell types (microglia, photoreceptors, and amacrine cells) showed the opposite trend. In fact, we were rather surprised to see up-regulation of genes specific to photoreceptors and amacrine cells. We suspect that inflammatory soluble factor production may have exerted an off-target stimulatory effect, as a paradoxical increase in retinal function has been reported in the early phases of intraocular inflammation [72]. Meanwhile, it was not surprising to observe the up-regulation of all 14 DEGs specifically expressed in microglia, as these cells have an important role in scavenging dying neurons [73]. One of these 14 DEGs, Clic1, is involved in the production of reactive oxygen species [74], which could be a key mediator of RGC death, as oxidative stress is known to contribute to the pathology of axonal injury [75]. In this study, we only examined changes in gene expression 2 days after ONC because, unlike the sham group, the number of RGCs significantly decreases at later time points in $\mathrm{ONC}$ group, which can complicate the direct comparison of gene expression between the two groups. However, it has been reported that inflammation and oxidative stress, as well as ER stress, are more activated at later time points after axonal injury [75,76]. Therefore, it is also important to evaluate changes in transcriptome profiles in these later stages, and we hope to investigate them in a future study using a different approach.

Among the 180 DEGs, Bcat1 showed the largest expression difference (Table 1). The validity of this CAGE data was verified with conventional qRT-PCR, which showed that expression increased in the ONC eyes by $\sim 16.1$-fold (Figure 3). This gene is therefore highly interesting as a therapeutic target, but its involvement in axonal injury and RGC death has not yet been reported. Bcat1 encodes the enzyme branched-chain amino acid transaminase and is the target of c-Myc. It can reportedly induce cell death by causing the production of excessive branched-chain keto acids through transamination [77]. It is also possible that this gene mediates the death of the RGCs via a similar mechanism.

Our in silico pathway analysis revealed that the "Cell Death and Survival" pathway was the most significant biological process in the ONC retinas (Table 2). Among relevant DEGs, genes involved in ER stress eventually leading to cell death, such as Atf3 and Ddit3, were upregulated 2 days after ONC (Additional files 4 and 10). It has been reported that Ddit3 up-regulates mRNA expression of $B b c 3$, a cell death-related gene [78], and also

Table 3 Predicted upstream regulators after ONC

\begin{tabular}{|c|c|c|c|c|}
\hline Name & $\begin{array}{l}\text { Predicted } \\
\text { change }\end{array}$ & $\begin{array}{l}\text { Activation } \\
\text { z-score }\end{array}$ & $\begin{array}{l}\text { P-value of } \\
\text { overlap }\end{array}$ & Target molecules in dataset \\
\hline ATF4 & Activated & 3.14 & $6.10 \mathrm{E}-18$ & $\begin{array}{l}\text { AARS, ASNS, ATF3, ATF5, BCAT1, CDKN1A, CEBPB, DDIT3, GARS, HERPUD1, MTHFD2, PSAT1, SARS, } \\
\text { SERPINF1, TNFRSF12A }\end{array}$ \\
\hline IFNG & Activated & 2.64 & $2.05 \mathrm{E}-04$ & BCL2, CDKN1A, CEBPB, CLIC4, CREM, DDIT3, FCGR2B, GNAO1, MMP12, SPRR1A, TAC1 \\
\hline $\begin{array}{l}\text { P38 } \\
\text { MAPK }\end{array}$ & Activated & 2.22 & $2.42 \mathrm{E}-06$ & BBC3, CDKN1A, EGR1, HMOX1, JUN, NEDD4 \\
\hline TP53 & Activated & 2.14 & $6.99 E-05$ & $\begin{array}{l}\text { APBB2, ATF3, BBC3, BCL2, CDKN1A, CLIC4, CNN3, COL3A1, CSTB, HIST1H1B, HMOX1, HSP90AA1, KITLG, } \\
\text { PARK7 }\end{array}$ \\
\hline ALDH2 & Inhibited & -2.22 & $1.94 \mathrm{E}-07$ & ATF5, MTHFD2, PHGDH, PSAT1, SLC1A4 \\
\hline ACOX1 & Inhibited & -2.00 & $1.33 \mathrm{E}-02$ & CDKN1A, CSTB, DDIT3, SQSTM1 \\
\hline
\end{tabular}

Data were analyzed with Fisher's exact test. Differences were considered significant with a $P$-value $<0.05$ and $\mid z$-score $\mid \geq 2$. The activation $z$-score was used to infer the likely activation states of upstream regulators based on a comparison with a model that assigns random regulation directions. The $P$-value overlap, which indicates likely upstream regulators, represents the significance of the overlap between the dataset genes identified here and known targets of transcriptional regulators. 
Table 4 List of predicted motif sequences associated with axonal injury

\begin{tabular}{|c|c|c|c|c|c|}
\hline Motif no. & Consensus & Foreground & Background & $P$-value & Known motifs ( $P$-value) \\
\hline \multicolumn{6}{|c|}{ Up-regulated at top peaks } \\
\hline AMD_001 & YNRNAGGTGT & 21 & 101 & $2.50 \mathrm{E}-06$ & NA \\
\hline AMD_002 & CCTNDGNNNGAG & 24 & 167 & 7.79E-05 & NA \\
\hline AMD_003 & WGAGNNTTACCNS & 20 & 91 & $2.65 \mathrm{E}-06$ & NA \\
\hline AMD_005 & GNNNGTGNTGATGNC & 19 & 92 & $1.30 \mathrm{E}-05$ & NA \\
\hline AMD_006 & YDNWNATTCHTAGGYNA & 16 & 102 & $1.61 \mathrm{E}-03$ & NA \\
\hline AMD_007 & CNNNMAGARTNNTTGNMNW & 22 & 115 & $3.75 \mathrm{E}-06$ & NA \\
\hline AMD_009 & ACGNNATAYWNNNA & 16 & 92 & $5.85 \mathrm{E}-04$ & NA \\
\hline GLAM2_001 & SCBCCCBCCCCYCCCCCNCCCB & 34 & 330 & $2.24 \mathrm{E}-05$ & SP1 (5.25E-08), Pax4 (6.97E-07), RREB1 (5.84E-06) \\
\hline \multicolumn{6}{|c|}{ Up-regulated at bottom peaks } \\
\hline AMD_003 & CTGSNYNNAGA & 22 & 128 & 4.80E-06 & NA \\
\hline AMD_004 & SNYAGGWGTCATK & 18 & 87 & $9.50 \mathrm{E}-06$ & NA \\
\hline AMD_006 & ATCNNNNNNBCCAM & 20 & 106 & $6.28 \mathrm{E}-06$ & Tal1::Gata1 (3.02E-06) \\
\hline AMD_009 & CTGNNNNNNNNNTNNANAKANNNA & 21 & 162 & $5.58 \mathrm{E}-04$ & NA \\
\hline GLAM2_004 & СCBCCYCCTCCHBHCHCCC & 33 & 371 & 1.07E-04 & Pax4 (1.56E-05), SP1 (2.93E-05) \\
\hline \multicolumn{6}{|c|}{ Down-regulated at top peaks } \\
\hline AMD_002 & WTCAATGAKWTACANTGWWMW & 20 & 193 & $5.23 \mathrm{E}-03$ & NA \\
\hline AMD_003 & SANKWAMAMTGARAAAMAYM & 23 & 237 & $3.82 \mathrm{E}-03$ & NA \\
\hline GLAM2_005 & TTCTTTYTTBTTYBTYTYYHTTTYT & 30 & 360 & $8.54 \mathrm{E}-04$ & NA \\
\hline \multicolumn{6}{|c|}{ Down-regulated at bottom peaks } \\
\hline GLAM2_006 & AAAMATGRAAAATRANAAAAANCAMA & 24 & 327 & 0 & NFATC2 (6.39E-05) \\
\hline DREME_001 & ACTCATCTA & 13 & 56 & $2.14 \mathrm{E}-06$ & NA \\
\hline DREME_002 & AAAACCACACTGTA & 18 & 124 & $1.42 \mathrm{E}-06$ & NA \\
\hline DREME_003 & ATGAGTTAC & 12 & 38 & $5.11 \mathrm{E}-07$ & NA \\
\hline DREME_004 & AGTTACACTGAA & 14 & 83 & $1.65 \mathrm{E}-05$ & NA \\
\hline DREME_006 & TACACTGTTCTACA & 12 & 87 & $5.72 \mathrm{E}-04$ & NA \\
\hline DREME_007 & ATTCGTTGG & 8 & 22 & $3.70 \mathrm{E}-05$ & NA \\
\hline DREME_008 & ATATTTCA & 16 & 99 & 3.37E-06 & NA \\
\hline DREME_009 & AATGAGAAAC & 14 & 74 & 5.10E-06 & NA \\
\hline DREME_010 & TCACTAAAA & 14 & 104 & $1.62 \mathrm{E}-04$ & NA \\
\hline DREME_011 & ACTGTAGGA & 15 & 82 & $2.43 \mathrm{E}-06$ & NA \\
\hline DREME_012 & AAACGGGATT & 10 & 73 & $2.26 \mathrm{E}-03$ & NA \\
\hline DREME_013 & HTATGAA & 15 & 78 & 1.40E-06 & NA \\
\hline DREME_014 & ATATGTTC & 16 & 102 & 4.82E-06 & NA \\
\hline
\end{tabular}

Foreground values indicate the number of occurrences of a motif sequence in DEGs after ONC.

Background values indicate the number of occurrences of a motif sequence in non-DEGs after ONC.

down-regulates mRNA expression of $B c l 2$, a cell survivalrelated gene [79]. Up-regulation of $B b c 3$ and downregulation of $B c l 2$ were confirmed in this study (Additional file 4) and may be caused by the increased transcription of Ddit3 and activation of ER stress as a mechanism of RGC death after ONC.

We also found that Serpinf1 (aka Pedf) was a cell survival-related DEG (Additional file 10). Serpinf1 reportedly plays a neuroprotective role in ONC [80].
Park7 was also classified as a cell survival-related DEG (Additional file 10). Previous reports showed that the translated protein of Park7 increased 4 days after ONC in rats [81] and that mutations in Park7 were associated with Parkinson's disease (PD) [82]. Animal models of PD have suggested that the translated protein exerts an anti-oxidative effect that leads to neuroprotection [83]. While the role of Park7 in the pathology of ONC is still unclear, it is possible that a similar anti-oxidative 
mechanism may protect the RGCs from axonal injuryinduced death.

The significance of our findings was reinforced by the in silico identification of networks of DEGs and the prediction of the most significant upstream regulators for each network, including the prediction that ATF4 was an up-stream regulator of the ER stress pathway (Table 3). It is conceivable that ATF4 could increase the transcription of ER stress-related genes, including Aft 3 and Ddit3, which may ultimately promote RGC death [84]. We found similar upregulation of ER stress-related genes in RNA-seq data obtained with a similar experimental design comparing ONC and sham-treated eyes [84]. Interestingly, Bcat1 was also included as a target of ATF4. The list of predicted upstream regulators of altered pathways also included P38MAPK and TP53, both implicated in RGC death after ONC $[85,86]$.

In addition, we performed a motif discovery analysis and determined that the SP1 (Sp1 transcription factor) motif was differentially up-regulated at bottom peaks (Table 4). SP1 is a zinc-finger transcription factor that binds to GC-rich elements $[87,88]$. It has been reported to regulate the transcription of damage-induced neuronal endopeptidase (DINE) through interaction with ATF3, c-Jun, and STAT3 [89]. DINE is also known as Ecel1 [90], which was up-regulated after ONC in this study. Therefore, SP1 may be implicated in transcription regulation after axonal injury.

Despite CAGE and RNA-seq using clearly different quantitative methods to evaluate gene expression, we found that they had a certain degree of commonality in their final output when identifying DEGs. However, CAGE did provide us with a unique insight into differences in TSSs, especially through its analysis of the differential use of multiple promoters within a given gene, and through the discovery of the associated DNAbinding motifs. However, at this point, we do not know which comprehensive gene expression database is more useful for selecting therapeutic targets. It may be that DEGs commonly observed in both the CAGE- and RNA-seq-derived datasets will yield the best targets. Nevertheless, conclusions on this point cannot be drawn until the functional characterization of a number of candidate genes from both groups is completed.

\section{Conclusions}

In summary, CAGE analysis followed by in silico molecular network analysis using retinal samples from a mouse ONC model revealed a list of DEGs partly matching a list previously identified with RNA-seq data [29]. A detailed analysis of TSSs provided us with a wealth of unique information on the differential use of promoters and the associated DNA binding motifs. As a next step, we aim to develop a high throughput pipeline to enable the efficient prioritization of candidate genes, using the current CAGE dataset to search for novel drug targets.

\section{Additional files}

\begin{abstract}
Additional file 1: Summary of mapping statistics from SAMStat output. The pie charts show the number of sequence alignments in various mapping quality (MAPQ) intervals and the number of unmapped sequences. The percentage and number of alignments in each category is given in brackets. Red indicates reads with a high mapping accuracy (MAPQ > 30). Black indicates unmapped reads. The RNA integrity number (RIN) of each sample is shown after the sample name.
\end{abstract}

Additional file 2: CAGE data analysis workflow. The workflow has two phases: primary data processing followed by clustering and analysis. During the first phase, the sequence data is evaluated for quality, filtered, mapped, and converted to an annotation file with a nAnT-iCAGE pipeline. During the second phase, the file is fed into the analytical pipeline, where the analysis of differential expression and motif discovery are carried out with the RECLU pipeline.

Additional file 3: List of Taqman probes used in this study. Additional file 4: List of DEGs after ONC.

Additional file 5: List of unannotated TSS clusters differentially expressed after ONC.

Additional file 6: List of expression changes in the retinal cellspecific transcriptome.

Additional file 7: Example of top and bottom peaks of TSS clusters. Genome Explorer views of Efemp 1 and Eifl genes are shown here, representing TSS clusters with a top peak (A) and a bottom peak (B), defined with a modified Paraclu program. Based on the distribution of the mapped tags, TSS clusters show two types of structures, sharp with a high peak (termed "top") and broad with a low peak (termed "bottom") [42]. The red frame indicates a top peak. The blue frame indicates a bottom peak.

Additional file 8: Alternative promoter usage in Tnfrsf12a gene transcription after ONC. Genome Explorer view comparing the distribution of mapped CAGE tags for the Tnfrsf12a gene in the ONC and sham groups. The $X$-axis indicates the number of mapped CAGE tags. Alternative promoters of Tnfrsf12a were activated at the bottom peak after ONC (red frame).

Additional file 9: Detailed list of functions and molecules associated with the "Cell Death and Survival" pathway after ONC. Additional file 10: List of DEGs involved in the Cell death and Cell survival pathways after ONC.

Additional file 11: Predicted regulators of axonal injury after ONC. Additional file 12: DNA sequence motifs likely to regulate gene expression changes after ONC. Logos of the most significantly up- or down-regulated DNA sequence motifs for each TSS peak are shown. The relative size of the letters represents their frequency in the motif sequences.

Competing interests

The authors declare that they have no competing interests.

\section{Authors' contributions}

MY, TN, MR and YT designed and organized this research. MY and YT sampled retinas from the mice. YT and ST prepared total RNA from the samples. MY and YT analyzed the obtained data. MY, KMN, YT, KM, and TN interpreted the results. MY and KMN wrote the manuscript. All authors read and approved the final manuscript.

\section{Acknowledgements}

This work was supported in part by JSPS KAKENHI Grants-in-Aid for Scientific Research B (T.N. 26293372) and for Challenging Exploratory Research (Y.T. 26670263 and T.N. 26670751). This study was also supported by the JST Center for Revitalization Promotion (Y.T. and T.N.), Senju Pharmaceutical Co., Ltd. 
(http://www.senju.co.jp/), and NIDEK Co., Ltd. (http://www.nidek.co.jp/index-j. html). This study received additional support from the Great East Japan Earthquake Reconstruction Support Project of the Genome Network Analysis Support Facility (GeNAS) of the RIKEN Center for Life Science Technologies and Illumina K.K. We thank the GeNAS for preparing the CAGE library and performing the sequencing. We thank the Cell Innovation Program (National Institute of Genetics, Japan) for providing the data analysis platform and thank Mr. Norikazu Monma for technical advice regarding the usage of the platform. We also thank Ms. Junko Sato for technical assistance and thank Mr. Tim Hilts for editing this manuscript.

\section{Author details}

'Department of Ophthalmology, Tohoku University Graduate School of Medicine, 1-1 Seiryo-machi, Aoba-ku, Sendai, Miyagi 980-8574, Japan. 2Department of Retinal Disease Control, Tohoku University Graduate School of Medicine, 1-1 Seiryo-machi, Aoba-ku, Sendai, Miyagi 980-8574, Japan. ${ }^{3}$ Department of Advanced Ophthalmic Medicine, Tohoku University Graduate School of Medicine, 1-1 Seiryo-machi, Aoba-ku, Sendai, Miyagi 980-8574, Japan.

Received: 28 May 2014 Accepted: 23 September 2014

Published: 18 November 2014

\section{References}

1. Quigley HA, Broman AT: The number of people with glaucoma worldwide in 2010 and 2020. Br J Ophthalmol 2006, 90:262-267.

2. Pederson JE, Anderson DR: The mode of progressive disc cupping in ocular hypertension and glaucoma. Arch Ophthalmol 1980, 98:490-495.

3. Heijl A, Leske MC, Bengtsson B, Hyman L, Bengtsson B, Hussein M: Reduction of intraocular pressure and glaucoma progression: results from the Early Manifest Glaucoma Trial. Arch Ophthalmol 2002 120:1268-1279.

4. Collaborative Normal-Tension Glaucoma Study Group: The effectiveness of intraocular pressure reduction in the treatment of normal-tension glaucoma. Am J Ophthalmol 1998, 126:498-505.

5. Hollands H, Johnson D, Hollands S, Simel DL, Jinapriya D, Sharma S: Do findings on routine examination identify patients at risk for primary open-angle glaucoma? The rational clinical examination systematic review. JAMA 2013, 309:2035-2042.

6. Gugleta K, Turksever C, Polunina A, Orgul S: Effect of ageing on the retinal vascular responsiveness to flicker light in glaucoma patients and in ocular hypertension. Br J Ophthalmol 2013, 97:848-851.

7. Burgoyne CF: A biomechanical paradigm for axonal insult within the optic nerve head in aging and glaucoma. Exp Eye Res 2011, 93:120-132.

8. Whitmore AV, Libby RT, John SW: Glaucoma: thinking in new ways-a role for autonomous axonal self-destruction and other compartmentalised processes? Prog Retin Eye Res 2005, 24:639-662.

9. Park HY, Jeon SH, Park CK: Enhanced depth imaging detects lamina cribrosa thickness differences in normal tension glaucoma and primary open-angle glaucoma. Ophthalmology 2012, 119:10-20.

10. Park SC, Hsu AT, Su D, Simonson JL, Al-Jumayli M, Liu Y, Liebmann JM, Ritch $\mathrm{R}$ : Factors associated with focal lamina cribrosa defects in glaucoma. Invest Ophthalmol Vis Sci 2013, 54:8401-8407.

11. Tatham AJ, Miki A, Weinreb RN, Zangwill LM, Medeiros FA: Defects of the lamina cribrosa in eyes with localized retinal nerve fiber layer loss. Ophthalmology 2014, 121:110-118.

12. Morgan JE: Optic nerve head structure in glaucoma: astrocytes as mediators of axonal damage. Eye (Lond) 2000, 14(Pt 3B):437-444

13. Quigley HA, Addicks EM, Green WR, Maumenee AE: Optic nerve damage in human glaucoma. II. The site of injury and susceptibility to damage. Arch Ophthalmol 1981, 99:635-649.

14. Dolman $\mathrm{CL}$, McCormick AQ, Drance SM: Aging of the optic nerve. Arch Ophthalmol 1980, 98:2053-2058.

15. Grossniklaus HE, Nickerson JM, Edelhauser HF, Bergman LA, Berglin L: Anatomic alterations in aging and age-related diseases of the eye. Invest Ophthalmol Vis Sci 2013, 54:ORSF23-ORSF27.

16. Albon J, Purslow PP, Karwatowski WS, Easty DL: Age related compliance of the lamina cribrosa in human eyes. Br J Ophthalmol 2000, 84:318-323.

17. Kotecha A, Izadi S, Jeffery $\mathrm{G}$ : Age-related changes in the thickness of the human lamina cribrosa. Br J Ophthalmol 2006, 90:1531-1534.
18. Orgul S, Cioffi GA, Wilson DJ, Bacon DR, Van Buskirk EM: An endothelin-1 induced model of optic nerve ischemia in the rabbit. Invest Ophthalmol Vis Sci 1996, 37:1860-1869.

19. Balaratnasingam C, Morgan WH, Bass L, Kang M, Cringle SJ, Yu DY: Timedependent effects of focal retinal ischemia on axonal cytoskeleton proteins. Invest Ophthalmol Vis Sci 2010, 51:3019-3028.

20. Rieck J: The pathogenesis of glaucoma in the interplay with the immune system. Invest Ophthalmol Vis Sci 2013, 54:2393-2409.

21. Tezel $\mathrm{G}$ : The immune response in glaucoma: a perspective on the roles of oxidative stress. Exp Eye Res 2011, 93:178-186.

22. Tezel G: Oxidative stress in glaucomatous neurodegeneration: mechanisms and consequences. Prog Retin Eye Res 2006, 25:490-513.

23. Noh YH, Kim KY, Shim MS, Choi SH, Choi S, Ellisman MH, Weinreb RN, Perkins GA, Ju WK: Inhibition of oxidative stress by coenzyme Q10 increases mitochondrial mass and improves bioenergetic function in optic nerve head astrocytes. Cell Death Dis 2013, 4:e820

24. Weinreb RN, Friedman DS, Fechtner RD, Cioffi GA, Coleman AL, Girkin CA, Liebmann JM, Singh K, Wilson MR, Wilson R, Kannel WB: Risk assessment in the management of patients with ocular hypertension. Am J Ophthalmol 2004, 138:458-467.

25. Ryu M, Yasuda M, Shi D, Shanab AY, Watanabe R, Himori N, Omodaka K, Yokoyama Y, Takano J, Saido T, Nakazawa T: Critical role of calpain in axonal damage-induced retinal ganglion cell death. J Neurosci Res 2012, 90:802-815.

26. Fischer D, Petkova V, Thanos S, Benowitz LI: Switching mature retinal ganglion cells to a robust growth state in vivo: gene expression and synergy with RhoA inactivation. J Neurosci 2004, 24:8726-8740.

27. Watkins TA, Wang B, Huntwork-Rodriguez S, Yang J, Jiang Z, Eastham-Anderson J, Modrusan Z, Kaminker JS, Tessier-Lavigne M, Lewcock JW: DLK initiates a transcriptional program that couples apoptotic and regenerative responses to axonal injury. Proc Natl Acad Sci U S A 2013, 110:4039-4044.

28. Wang Z, Gerstein M, Snyder M: RNA-Seq: a revolutionary tool for transcriptomics. Nat Rev Genet 2009, 10:57-63.

29. Yasuda M, Tanaka Y, Ryu M, Tsuda S, Nakazawa T: RNA sequence reveals mouse retinal transcriptome changes early after axonal injury. PLoS One 2014, 9:e93258.

30. Shiraki T, Kondo S, Katayama S, Waki K, Kasukawa T, Kawaji H, Kodzius R, Watahiki A, Nakamura M, Arakawa T, Fukuda S, Sasaki D, Podhajska A, Harbers M, Kawai J, Carninci P, Hayashizaki Y: Cap analysis gene expression for high-throughput analysis of transcriptional starting point and identification of promoter usage. Proc Natl Acad Sci U S A 2003, 100:15776-15781.

31. de Hoon M, Hayashizaki Y: Deep cap analysis gene expression (CAGE): genome-wide identification of promoters, quantification of their expression, and network inference. Biotechniques 2008, 44:627-628. 630, 632.

32. Hoskins RA, Landolin JM, Brown JB, Sandler JE, Takahashi H, Lassmann T, Yu C, Booth BW, Zhang D, Wan KH, Yang L, Boley N, Andrews J, Kaufman TC, Graveley BR, Bickel PJ, Carninci P, Carlson JW, Celniker SE: Genome-wide analysis of promoter architecture in Drosophila melanogaster. Genome Res 2011, 21:182-192.

33. Birney E, Stamatoyannopoulos JA, Dutta A, Guigo R, Gingeras TR, Margulies EH, Weng Z, Snyder M, Dermitzakis ET, Thurman RE, Kuehn MS, Taylor CM, Neph S, Koch CM, Asthana S, Malhotra A, Adzhubei I, Greenbaum JA Andrews RM, Flicek P, Boyle PJ, Cao H, Carter NP, Clelland GK, Davis S, Day $\mathrm{N}$, Dhami P, Dillon SC, Dorschner MO, Fiegler $\mathrm{H}$, et al: Identification and analysis of functional elements in $1 \%$ of the human genome by the ENCODE pilot project. Nature 2007, 447:799-816.

34. Bernstein BE, Birney E, Dunham I, Green ED, Gunter C, Snyder M: An integrated encyclopedia of DNA elements in the human genome. Nature 2012, 489:57-74.

35. Allcutt $D$, Berry M, Sievers J: A qualitative comparison of the reactions of retinal ganglion cell axons to optic nerve crush in neonatal and adult mice. Brain Res 1984, 318:231-240.

36. Kanamori-Katayama M, Itoh M, Kawaji H, Lassmann T, Katayama S, Kojima M, Bertin N, Kaiho A, Ninomiya N, Daub CO, Carninci P, Forrest AR, Hayashizaki Y: Unamplified cap analysis of gene expression on a single-molecule sequencer. Genome Res 2011, 21:1150-1159.

37. Takahashi H, Lassmann T, Murata M, Carninci P: 5' end-centered expression profiling using cap-analysis gene expression and next-generation sequencing. Nat Protoc 2012, 7:542-561.

38. Murata M, Nishiyori-Sueki H, Kojima-Ishiyama M, Carninci P, Hayashizaki Y, Itoh M: Detecting expressed genes using CAGE. Methods Mol Biol 2014, 1164:67-85. 
39. Li H, Durbin R: Fast and accurate short read alignment with BurrowsWheeler transform. Bioinformatics 2009, 25:1754-1760.

40. Li H, Handsaker B, Wysoker A, Fennell T, Ruan J, Homer N, Marth G, Abecasis $\mathrm{G}$, Durbin R: The sequence alignment/Map format and SAMtools. Bioinformatics 2009, 25:2078-2079.

41. Lassmann T, Hayashizaki Y, Daub CO: SAMStat: monitoring biases in next generation sequencing data. Bioinformatics 2011, 27:130-131.

42. Ohmiya $H$, Vitezic $M$, Frith MC, Itoh M, Carninci $P$, Forrest AR, Hayashizaki $Y$ Lassmann T: RECLU: a pipeline to discover reproducible transcriptional start sites and their alternative regulation using capped analysis of gene expression (CAGE). BMC Genomics 2014, 15:269.

43. Frith MC, Valen E, Krogh A, Hayashizaki Y, Carninci P, Sandelin A: A code for transcription initiation in mammalian genomes. Genome Res 2008, 18:1-12.

44. Li Q, Brown JB, Huang H, Bickel PJ: Measuring reproducibility of highthroughput experiments. Annals App/ Stat 2011, 5:1752-1779.

45. Ruzzo WL, Tompa M: A linear time algorithm for finding all maximal scoring subsequences. Proc Int Conf Intell Syst Mol Biol 1999, 7:234-241.

46. Robinson MD, McCarthy DJ, Smyth GK: edgeR: a Bioconductor package for differential expression analysis of digital gene expression data. Bioinformatics 2010, 26:139-140

47. Shi J, Yang W, Chen M, Du Y, Zhang J, Wang K: AMD, an automated motif discovery tool using stepwise refinement of gapped consensuses. PLoS One 2011, 6:e24576.

48. Frith MC, Saunders NF, Kobe B, Bailey TL: Discovering sequence motifs with arbitrary insertions and deletions. PLoS Comput Biol 2008 4:e1000071.

49. Pavesi G, Mereghetti P, Mauri G, Pesole G: Weeder Web: discovery of transcription factor binding sites in a set of sequences from coregulated genes. Nucleic Acids Res 2004, 32:W199-W203.

50. Bailey TL: DREME: motif discovery in transcription factor ChIP-seq data. Bioinformatics 2011, 27:1653-1659.

51. Bailey TL, Boden M, Buske FA, Frith M, Grant CE, Clementi L, Ren J, Li WW, Noble WS: MEME SUITE: tools for motif discovery and searching. Nucleic Acids Res 2009, 37:W202-W208

52. Mathelier A, Zhao X, Zhang AW, Parcy F, Worsley-Hunt R, Arenillas DJ, Buchman S, Chen CY, Chou A, lenasescu H, Lim J, Shyr C, Tan G, Zhou M, Lenhard B, Sandelin A, Wasserman WW: JASPAR 2014: an extensively expanded and updated open-access database of transcription factor binding profiles. Nucleic Acids Res 2014, 42:D142-D147.

53. Shanab AY, Nakazawa T, Ryu M, Tanaka Y, Himori N, Taguchi K, Yasuda M, Watanabe R, Takano J, Saido T, Minegishi N, Miyata T, Abe T, Yamamoto M: Metabolic stress response implicated in diabetic retinopathy: the role of calpain, and the therapeutic impact of calpain inhibitor. Neurobiol Dis 2012, 48:556-567.

54. Prat-Vidal C, Galvez-Monton C, Nonell L, Puigdecanet E, Astier L, Sole F, Bayes-Genis A: Identification of temporal and region-specific myocardial gene expression patterns in response to infarction in swine. PLOS One 2013, 8:e54785.

55. Saili KS, Tilton SC, Waters KM, Tanguay RL: Global gene expression analysis reveals pathway differences between teratogenic and non-teratogenic exposure concentrations of bisphenol A and 17beta-estradiol in embryonic zebrafish. Reprod Toxicol 2013, 38:89-101.

56. Cassone CG, Taylor JJ, O'Brien JM, Williams A, Yauk CL, Crump D, Kennedy SW: Transcriptional profiles in the cerebral hemisphere of chicken embryos following in ovo perfluorohexane sulfonate exposure. Toxicol $\mathrm{SC}$ 2012, 129:380-391.

57. R Core Team: R: A Language and Environment for Statistical Computing Austria: R Foundation for Statistical Computing V; Available: http://www.Rproject.org.

58. Kawaji H, Lizio M, Itoh M, Kanamori-Katayama M, Kaiho A, Nishiyori-Sueki H Shin JW, Kojima-Ishiyama M, Kawano M, Murata M, Ninomiya-Fukuda N, Ishikawa-Kato S, Nagao-Sato S, Noma S, Hayashizaki Y, Forrest AR, Carninci P: Comparison of CAGE and RNA-seq transcriptome profiling using clonally amplified and single-molecule next-generation sequencing. Genome Res 2014, 24:708-717.

59. Siegert S, Cabuy E, Scherf BG, Kohler H, Panda S, Le YZ, Fehling HJ, Gaidatzis D, Stadler MB, Roska B: Transcriptional code and disease map for adult retinal cell types. Nat Neurosci 2012, 15:487-495. S481-482.

60. Nadal-Nicolas FM, Jimenez-Lopez M, Sobrado-Calvo P, Nieto-Lopez L, Canovas-Martinez I, Salinas-Navarro M, Vidal-Sanz M, Agudo M: Brn3a as a marker of retinal ganglion cells: qualitative and quantitative time course studies in naive and optic nerve-injured retinas. Invest Ophthalmol Vis Sci 2009, 50:3860-3868.

61. Chidlow G, Casson R, Sobrado-Calvo P, Vidal-Sanz M, Osborne NN: Measurement of retinal injury in the rat after optic nerve transection: an RT-PCR study. Mol Vis 2005, 11:387-396.

62. Sandelin A, Carninci P, Lenhard B, Ponjavic J, Hayashizaki Y, Hume DA: Mammalian RNA polymerase II core promoters: insights from genomewide studies. Nat Rev Genet 2007, 8:424-436.

63. Severin J, Lizio M, Harshbarger J, Kawaji H, Daub CO, Hayashizaki Y, Bertin N, Forrest AR: Interactive visualization and analysis of large-scale sequencing datasets using ZENBU. Nat Biotechnol 2014, 32:217-219.

64. Forrest $A R$, Kawaji $H$, Rehli M, Baillie JK, de Hoon MJ, Lassmann T, Itoh M, Summers KM, Suzuki H, Daub CO, Kawai J, Heutink P, Hide W, Freeman TC, Lenhard B, Bajic VB, Taylor MS, Makeev VJ, Sandelin A, Hume DA, Carninci P, Hayashizaki Y: A promoter-level mammalian expression atlas. Nature 2014, 507:462-470.

65. Liang SH, Zhang W, McGrath BC, Zhang P, Cavener DR: PERK (elF2alpha kinase) is required to activate the stress-activated MAPKs and induce the expression of immediate-early genes upon disruption of ER calcium homoeostasis. Biochem J 2006, 393:201-209.

66. Logue SE, Cleary P, Saveljeva S, Samali A: New directions in ER stressinduced cell death. Apoptosis 2013, 18:537-546.

67. Han J, Flemington C, Houghton AB, Gu Z, Zambetti GP, Lutz RJ, Zhu L, Chittenden T: Expression of bbc3, a pro-apoptotic BH3-only gene, is regulated by diverse cell death and survival signals. Proc Natl Acad SC U S A 2001, 98:11318-11323.

68. Merry DE, Korsmeyer SJ: Bcl-2 gene family in the nervous system. Annu Rev Neurosci 1997, 20:245-267.

69. Liu F, Nguyen JL, Hulleman JD, Li L, Rochet JC: Mechanisms of DJ-1 neuroprotection in a cellular model of Parkinson's disease. J Neurochem 2008, 105:2435-2453.

70. Tombran-Tink J, Barnstable CJ: PEDF: a multifaceted neurotrophic factor. Nat Rev Neurosci 2003, 4:628-636.

71. Barabasi AL, Oltvai ZN: Network biology: understanding the cell's functional organization. Nat Rev Genet 2004, 5:101-113.

72. Bringmann A, landiev I, Pannicke T, Wurm A, Hollborn M, Wiedemann P, Osborne NN, Reichenbach A: Cellular signaling and factors involved in Muller cell gliosis: neuroprotective and detrimental effects. Prog Retin Eye Res 2009, 28:423-451.

73. Galindo-Romero C, Valiente-Soriano FJ, Jimenez-Lopez M, Garcia-Ayuso D, Villegas-Perez MP, Vidal-Sanz M, Agudo-Barriuso M: Effect of brain-derived neurotrophic factor on mouse axotomized retinal ganglion cells and phagocytic microglia. Invest Ophthalmol Vis Sci 2013, 54:974-985.

74. Milton RH, Abeti R, Averaimo S, DeBiasi S, Vitellaro L, Jiang L, Curmi PM, Breit SN, Duchen MR, Mazzanti M: CLIC1 function is required for betaamyloid-induced generation of reactive oxygen species by microglia. J Neurosci 2008, 28:11488-11499.

75. Himori N, Yamamoto K, Maruyama K, Ryu M, Taguchi K, Yamamoto M, Nakazawa T: Critical role of Nrf2 in oxidative stress-induced retinal ganglion cell death. J Neurochem 2013, 127:669-680.

76. Lin S, Liang Y, Zhang J, Bian C, Zhou H, Guo Q, Xiong Y, Li S, Su B: Microglial TIR-domain-containing adapter-inducing interferon-beta (TRIF) deficiency promotes retinal ganglion cell survival and axon regeneration via nuclear factor-kappaB. J Neuroinflammation 2012, 9:39.

77. Eden A, Benvenisty N: Involvement of branched-chain amino acid aminotransferase (Bcat1/Eca39) in apoptosis. FEBS Lett 1999, 457:255-261.

78. Galehdar Z, Swan P, Fuerth B, Callaghan SM, Park DS, Cregan SP: Neuronal apoptosis induced by endoplasmic reticulum stress is regulated by ATF4-CHOP-mediated induction of the Bcl-2 homology 3-only member PUMA. J Neurosci 2010, 30:16938-16948.

79. Leaver SG, Cui Q, Bernard O, Harvey AR: Cooperative effects of bcl-2 and AAV-mediated expression of CNTF on retinal ganglion cell survival and axonal regeneration in adult transgenic mice. Eur J Neurosci 2006, 24:3323-3332

80. Miyazaki M, Ikeda Y, Yonemitsu Y, Goto Y, Murakami Y, Yoshida N, Tabata T, Hasegawa M, Tobimatsu S, Sueishi K, Ishibashi T: Pigment epitheliumderived factor gene therapy targeting retinal ganglion cell injuries: neuroprotection against loss of function in two animal models. Hum Gene Ther 2011, 22:559-565.

81. Magharious M, D'Onofrio PM, Hollander A, Zhu P, Chen J, Koeberle PD: Quantitative ITRAQ analysis of retinal ganglion cell degeneration after optic nerve crush. J Proteome Res 2011, 10:3344-3362. 
82. Bonifati V, Rizzu P, van Baren MJ, Schaap O, Breedveld GJ, Krieger E, Dekker MC, Squitieri F, Ibanez P, Joosse M, van Dongen JW, Vanacore N, van Swieten JC, Brice A, Meco G, van Duijn CM, Oostra BA, Heutink P: Mutations in the DJ-1 gene associated with autosomal recessive early-onset parkinsonism. Science 2003, 299:256-259.

83. Kahle PJ, Waak J, Gasser T: DJ-1 and prevention of oxidative stress in Parkinson's disease and other age-related disorders. Free Radic Biol Med 2009, 47:1354-1361.

84. Kim I, Xu W, Reed JC: Cell death and endoplasmic reticulum stress: disease relevance and therapeutic opportunities. Nat Rev Drug Discov 2008, 7:1013-1030

85. Katome T, Namekata K, Guo X, Semba K, Kittaka D, Kawamura K, Kimura A, Harada C, Ichijo H, Mitamura Y, Harada T: Inhibition of ASK1-p38 pathway prevents neural cell death following optic nerve injury. Cell Death Differ 2013, 20:270-280

86. Park KK, Liu K, Hu Y, Smith PD, Wang C, Cai B, Xu B, Connolly L, Kramvis I, Sahin $M$, He Z: Promoting axon regeneration in the adult CNS by modulation of the PTEN/mTOR pathway. Science 2008, 322:963-966.

87. Deniaud E, Baguet J, Mathieu AL, Pages G, Marvel J, Leverrier Y: Overexpression of Sp1 transcription factor induces apoptosis. Oncogene 2006, 25:7096-7105.

88. Koutsodontis G, Tentes I, Papakosta P, Moustakas A, Kardassis D: Sp1 plays a critical role in the transcriptional activation of the human cyclindependent kinase inhibitor p21(WAF1/Cip1) gene by the p53 tumor suppressor protein. J Biol Chem 2001, 276:29116-29125.

89. Kiryu-Seo S, Kato R, Ogawa T, Nakagomi S, Nagata K, Kiyama H: Neuronal injury-inducible gene is synergistically regulated by ATF3, c-Jun, and STAT3 through the interaction with Sp1 in damaged neurons. J Biol Chem 2008, 283:6988-6996.

90. Kiryu-Seo S: Identification and functional analysis of damage-induced neuronal endopeptidase (DINE), a nerve injury associated molecule. Anat Sci Int 2006, 81:1-6.

doi:10.1186/1471-2164-15-982

Cite this article as: Yasuda et al:: Retinal transcriptome profiling at transcription start sites: a cap analysis of gene expression early after axonal injury. BMC Genomics 2014 15:982.

\section{Submit your next manuscript to BioMed Central and take full advantage of:}

- Convenient online submission

- Thorough peer review

- No space constraints or color figure charges

- Immediate publication on acceptance

- Inclusion in PubMed, CAS, Scopus and Google Scholar

- Research which is freely available for redistribution

Submit your manuscript at www.biomedcentral.com/submit
C Biomed Central 